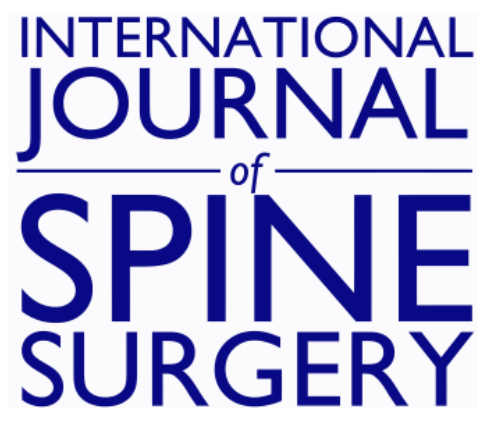

\title{
Analysis of the outcome in patients with cervical spondylotic myelopathy, undergone canal expansive laminoplasty supported with instrumentation in a group of Indian population - a prospective study
}

Subhadip Mandal, U. Banerjee, A.S. Mukherjee, Subhajyoti Mandal and Srikanta Kundu

Int J Spine Surg 2016, 10 ()

doi: https://doi.org/10.14444/3017

http://ijssurgery.com/content/10/17

This information is current as of April 26, 2023.

Email Alerts Receive free email-alerts when new articles cite this article. Sign up at:

http://ijssurgery.com/alerts

The International Journal of Sdpine Sybrgerthttp://ijssurgery.com/ by guest on April 26, 2 2397 Waterbury Circle, Suite 1, 


\section{Analysis of the outcome in patients with cervical spondylotic myelopathy, undergone canal expansive laminoplasty supported with instrumentation in a group of Indian population - a prospective study.}

Subhadip Mandal, MS (ortho), DNB (ortho), MBBS, U. Banerjee, MS (ortho), DNB ortho, A.S. Mukherjee, MS (ortho), MBBS, Subhajyoti Mandal, $M B B S$, Srikanta Kundu $M S$ (ortho), $M B B S$

Department of Orthopaedics, NRS Medical College \& Hospital, Kolkata, India

\section{Abstract}

Background

Chronic compression of the cervical spinal cord leads to a clinical syndrome of cervical spondylotic myelopathy (CSM). Clinical symptoms of cervical spondylotic myelopathy (CSM) or cervical myeloradiculopathies result in spinal cord and root dysfunction. The primary aims of surgical intervention for multilevel myelopathy are to decompress the spinal cord and maintain stability of the cervical spine. Secondary aims are to minimize complications which include long-term pain and motion loss. Laminoplasty as either single-door or double-door technique and with/without instrumentation is an established mode of surgical treatment.

The purpose of our study was to evaluate the result of single-door laminoplasty technique, supported with instrumented fixation in patients with multilevel degenerative cervical spondylotic myeloradiculopathy.

Methods

A prospective and without control study has been conducted in the institution in 17 patients with CSM, operated by canal expansive single-door laminoplasty (Hirabayashi technique) between April 2010 to April 2015. These patients were followed up for at least 3 years with both clinical and radiographic evaluations.

Results

On clinical evaluation, 15 of the 17 patients (87\%) experienced relief of their symptoms. According to the Nurick classification, 11 patients' demonstrated improvement by one grade, two patients improved by two grades, two patients were unchanged and two had worsening of the Nurick grade.

Conclusions

The results of this study regarding the use of open-door laminoplasty with instrumented fixation suggest that this technique is a satisfactory alternative for cases of multilevel cervical spondylotic myelopathy without deformation.

Level of Evidence

Level III therapeutic study.

KEYWORDS: CERVICAL SPINE, SPONDYLOTIC MYELORADICULOPATHY, SINGLE-DOOR LAMINOPLASTY, INSTRUMENTED FIXATION, NURICK CLINICAL EVALUATION

VOLUME 10 ARTICLE 17 DOI: 10.14444/3017

\section{Introduction}

Chronic compression of the cervical spinal cord leads to a clinical syndrome of cervical spondylotic myelopathy (CSM). It is a common condition affecting $2 \%$ of all hospital admissions according to a number of studies. ${ }^{1,2}$ The two main causes of this condi-

Downloaded from http://ijssurgery.com/ by guest on April 26, 2023 tion are cervical spondylosis and ossification of the posterior longitudinal ligament (OPLL). ${ }^{3}$ Apart from these, herniated disk materials, osteophytes, redundant ligamentum flavum, and congenital or developmental cervical canal stenosis can cause spinal cord compression. $^{4}$ 
Clinical symptoms of cervical spondylotic myelopathy (CSM) or cervical myeloradiculopathies result in spinal cord and root dysfunction. The classic presentations are subtle loss of balance and coordination, decreased hand dexterity, weakness, numbness, and potential paralysis. CSM is the leading cause of spinal cord dysfunction in patients older than 55 years. ${ }^{5}$ Treatment is directed at arresting further deterioration after the onset of clinical symptoms, and secondarily to improve neurologic dysfunction.

The primary aims of surgical intervention for multilevel myelopathy are to decompress the spinal cord and maintain stability of the cervical spine. Secondary aims are to minimize complications which include long-term pain and motion loss. Controversies have arisen between researchers regarding the use of an anterior or posterior approach, prophylactic surgery, and conservative (non-surgical) versus surgical treatment. ${ }^{6,7}$

\section{Materials and Methods}

\section{Ethical Statements}

The Ethical Committee of the the NRS Medical College in Kolkata, India, granted ethical approval for this study and it has been performed in accordance with the standards of the 1964 Declaration of Helsin$\mathrm{ki}$ as revised in 2000. Written informed consent in three languages (Local, National and English) was obtained from every patient prior to including them in the study.

\section{Series}

A prospective and without control study was conducted in the institution among 17 patients with Chronic Spondylotic Myelopathy, who were operated by canal expansive laminoplasty (Hirabayashi technique) between April 2010 to April 2015. These patients were followed up for at least 3 years with both clinical and radiographic evaluations.

\section{Materials}

All of the patients who admitted at Outpatient department and emergency department of our institution were exhibiting clinical evidence of myelopathy, with or without radiculopathy, underwent complete radiographic evaluation. It consisted of neutral antero-posterior and lateral imaging, flexion/extension x-ray imaging, computed tomography (CT) and magnetic resonance imaging (MRI). The patients with cervical multilevel stenosis (cervical spine canal diameter $<12 \mathrm{~mm}$ ) at 3 or more levels were included in this study (Figure 1). Patients with complaint of pre-operative neck pain and radiographic signs of instability ${ }^{8}$ and kyphotic deformity were excluded from this study.

The Nurick scale (Table 1) ${ }^{9}$ was used to clinically evaluate and objectively compare the preoperative data and the postoperative follow-up data.

Follow-up was conducted over a minimum of three years and postoperative follow-up data were recorded at 4 weeks, 8 weeks, 12 weeks, and then every three months for the first year, and then every six month for the next two years at least.

\section{Surgical planning and techniques}

After intubation was performed, the Mayfield pin holder headrest was applied and the patient was turned prone on the operating table in reverse Trendelenburg position at about 20-30 degrees to help the venous drainage and good visualization. The head and neck were maintained in neutral to slight flexion which opens the interspinous distances. Injudicious shoulder depression should be avoided, as it might cause traction injury on the brachial plexus.

Preoperative planning was essential in determining the number of levels to be expanded and whether foraminotomies were indicated for relief of radicular symptomatology. In cases of no concurrent radicu-

\begin{tabular}{|l|l|}
\hline Table 1. Nurick clinical scale. \\
\hline Grading & Nurick Clinical Scale \\
\hline Grade 0 & $\begin{array}{l}\text { Signs and symptoms of root involvement but without evidence of } \\
\text { spinal cord disease. }\end{array}$ \\
\hline Grade 1 & Signs of spinal cord diseases but no difficulty walking. \\
\hline Grade 2 & $\begin{array}{l}\text { Slight difficulty in walking which does not prevent full-time } \\
\text { employment. }\end{array}$ \\
\hline Grade 3 & $\begin{array}{l}\text { Extreme difficulty in walking that requires assistance and prevents } \\
\text { full-time employment and occupation. }\end{array}$ \\
\hline Grade 4 & $\begin{array}{l}\text { Able to walk only with someone else's help or with the aid of a } \\
\text { walker. }\end{array}$ \\
\hline Grade 5 & Chairbound or bedridden. \\
\hline
\end{tabular}


lopathy, the side opened was the surgeon's preference; in cases of unilateral radicular symptoms, the affected side was preferentially opened; in cases of bilateral radiculopathy and radiographically documented foraminal narrowing, foraminotomies were performed on both sides before rotation of the laminae.

Via a midline posterior approach a bilateral subperiosteal dissection of the posterior elements was performed. Care is taken to preserve the attachments to $\mathrm{C} 2$ of the inferior oblique muscle and greater straight muscle of the head as this prevents local kyphotic deformity between $\mathrm{C} 2$ and $\mathrm{C} 3$. Holes were prepared in the bases of the spinous processes for each level to be included in the "open-door." The extent of the decompression was from the laminar level of one above to one below the stenotic site diagnosed by preoperative imaging.

Using a micro drill or high speed burr, a bony gutter with a thin bottom was drilled at the junction of the laminae and facet joints on the side that was most symptomatic. Care was taken to ensure that the cut was made perpendicular to the lamina without entering the facet. Resection of the remaining "eggshell" bone was performed with Kerison rongeurs. On the contralateral lamina, the outer cortex was cut using a micro drill or burr (Figure 2). It was important to maintain the integrity of the inner cortex as this act as a hinge. The top and bottom lamina to be included in the "door" were separated from their adjacent levels with a Kerison rongeurs by cutting the lamina and adherent ligamentum flavum. Supraspinous and interspinous ligaments were detached along with ligamentum flavum from the remaining at the top and bottom of the "door" segment. This creates three free sides for the "door" and one "hinge". The door was opened by rotating the "door" on the hinge, which effectively produces canal expansion (Figure 3). We preserved the posterior cervical ligaments in the rotated segment, but these structures had to mobilise at the top and bottom of the segment so the rotation of the "door" can be done effectively without much strain.

Finally, secure fixation of the open-door laminoplasty was accomplished with AO/ASIF $2.5 \mathrm{~mm}$ maxillofacial miniplates (Synthes). No bone or sutures were needed to hold the laminoplasty open, as the plates provided immediate and secure fixation (Figure 4).

Postoperatively, patients were placed in a Philadelphia cervical collar for four weeks and allow gradual mobilization in flexion-extension, rotation, and side bending as tolerated.
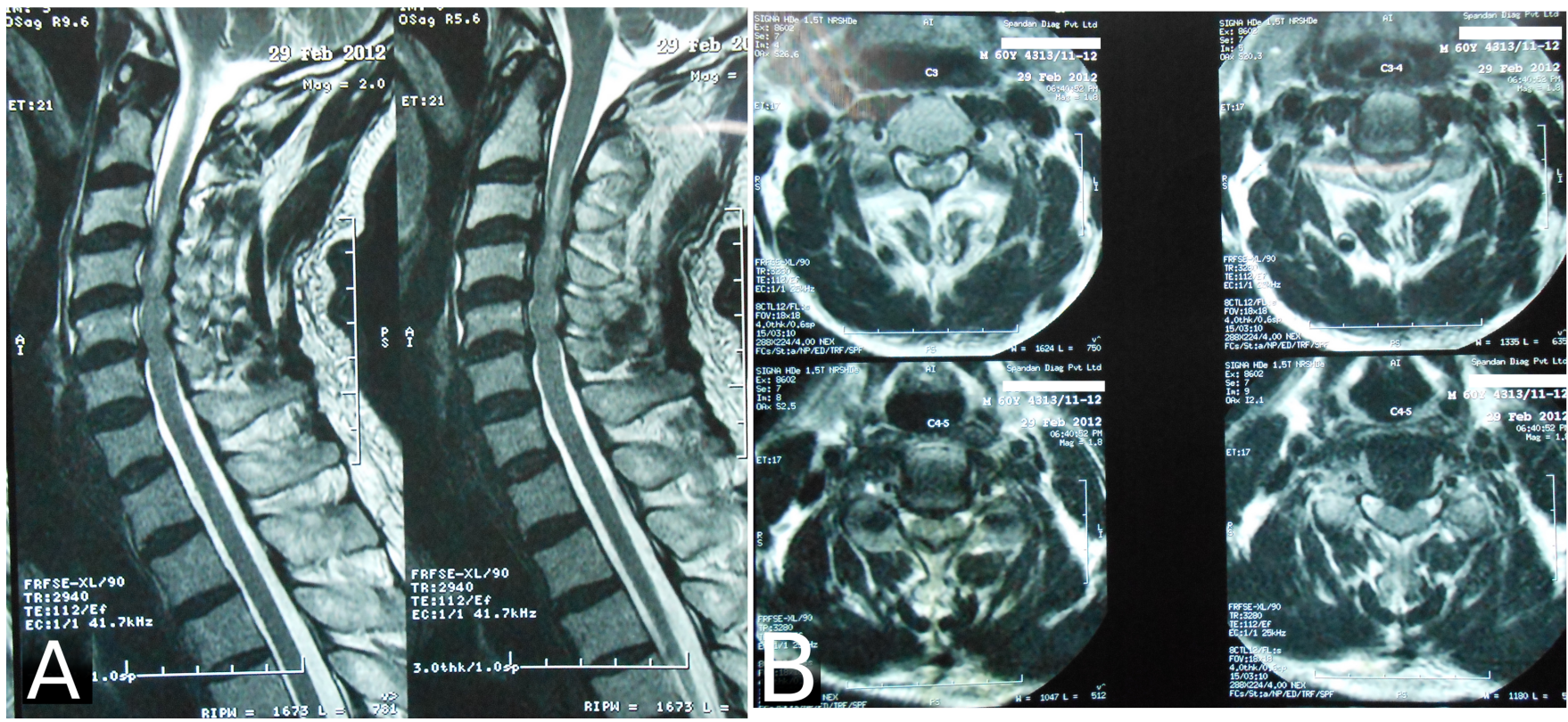

Fig. 1. MRI picture showing multilevel cervical stenosis.

Downloaded from http://ijssurgery.com/ by guest on April 26, 2023 


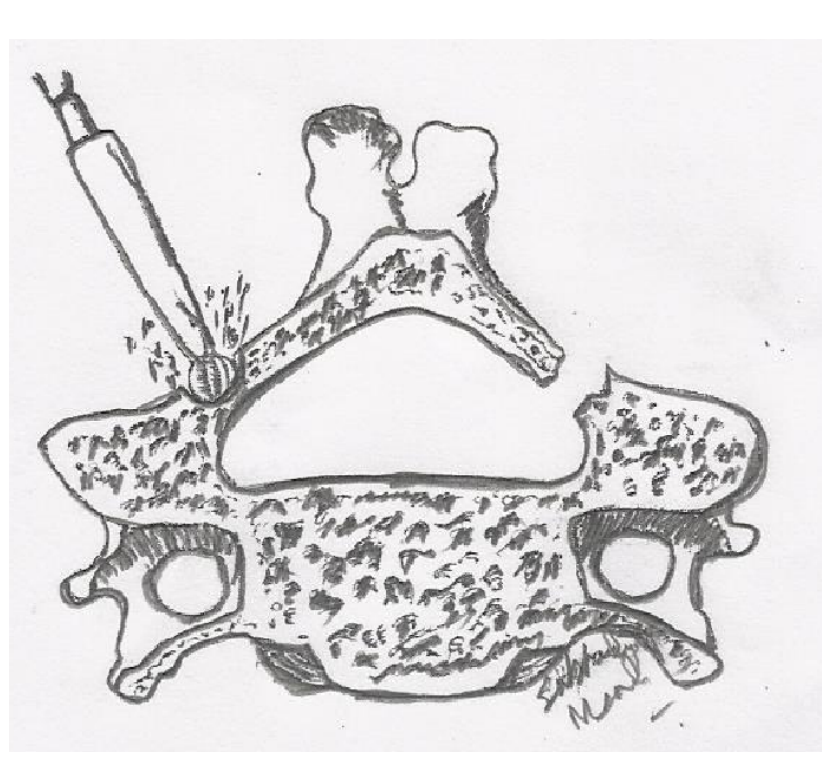

Fig. 2. Creation of Bilaminar trough and unilaminar hinge with help of burr.

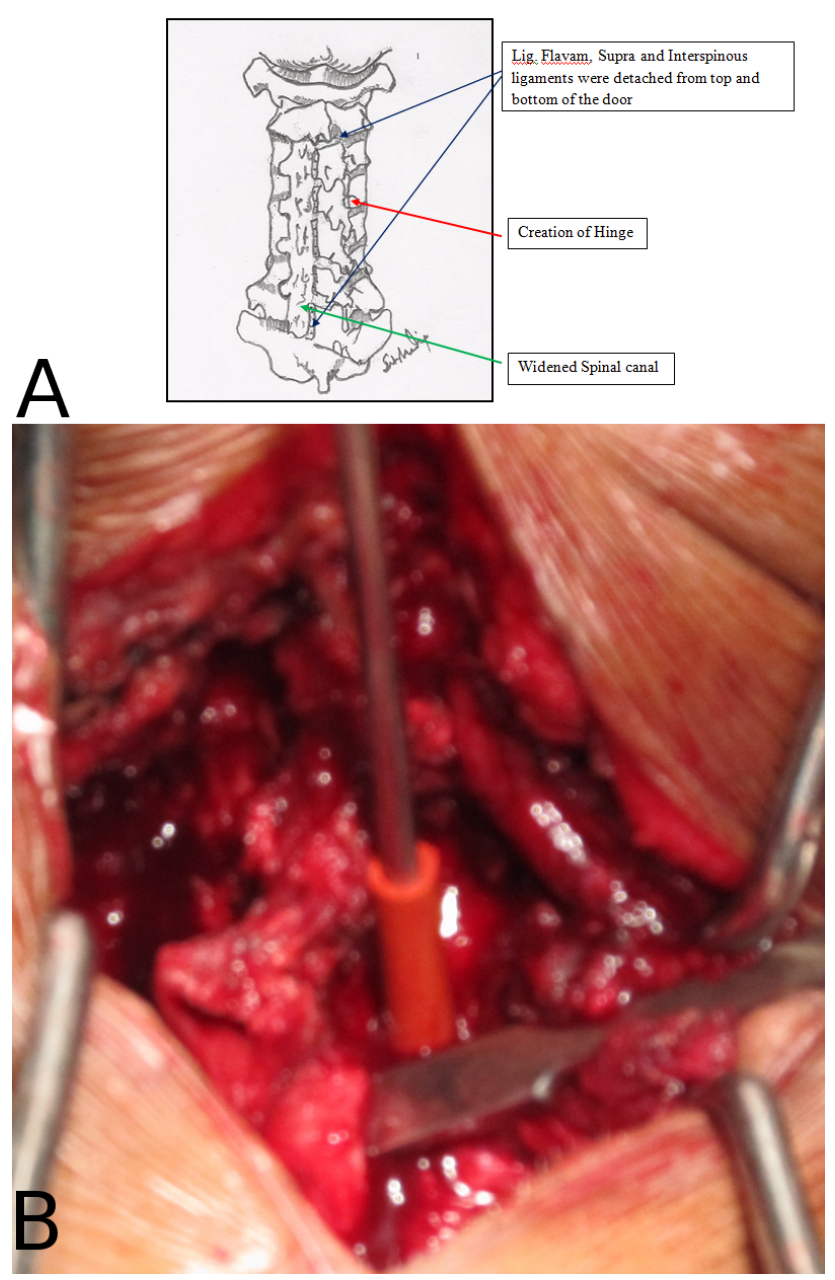

Fig. 3. A) Schematic diagram showing rotation of hinge and subsequent canal expansion. B) Perioperative diagram showing rotation of hinge and canal expansion.

\section{Results}

In our series, among the 17 patients, male patients were 15 and female patients were 2 in number. Age ranged from 45 to 72 (mean 60 years). All patients were presented with cervical myelopathy. 4 patients had concomitant OPLL and 8 patients had radiculopathy (5 patients on the right side and 3 patients on left). The mean preoperative Nurick grade was 3 (range 1-5). Mean symptom duration was 24 months (range, 2-84 months). Presence of myelopathy were at the range of three to five levels. Mean follow-up was 4.5 years.

Regarding co-morbidities, 3 patients had diabetes mellitus, 9 patients suffered from hypertension and one patient had long standing rheumatoid arthritis. Smoking of more than 5 years duration was present in 6 male patients.
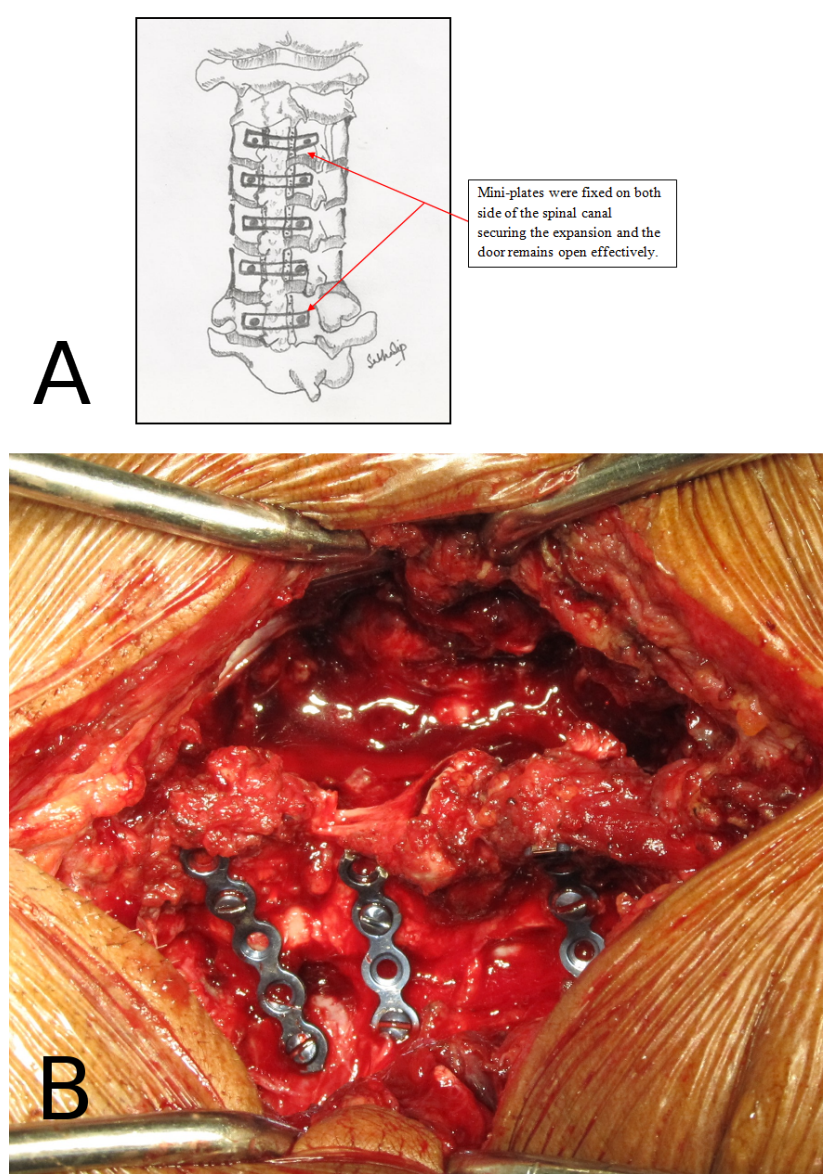

Fig. 4. A) Schematic diagram showing fixation with a prebent plate for stabilisation. B) Intraoperative diagram showing laminoplasty secured with miniplates. 
All patients were underwent instrumented opendoor laminoplasty (as described earlier). Fourteen patients had a right-sided opening; three had a leftsided opening (Figure 5). Eight patients had concurrent foraminotomies according to the side of involvement. Thirteen patients underwent laminoplasty at three levels, three at four levels, and one patient at five level (mean 3.3). Mean surgical time was 3 hours 30 minutes and mean blood loss was $350 \mathrm{ml}$.

On clinical evaluation, 15 of the 17 patients (87\%) experienced relief of their symptoms. According to the Nurick classification, 11 patients' demonstrated improvement by one grade, two patients improved by

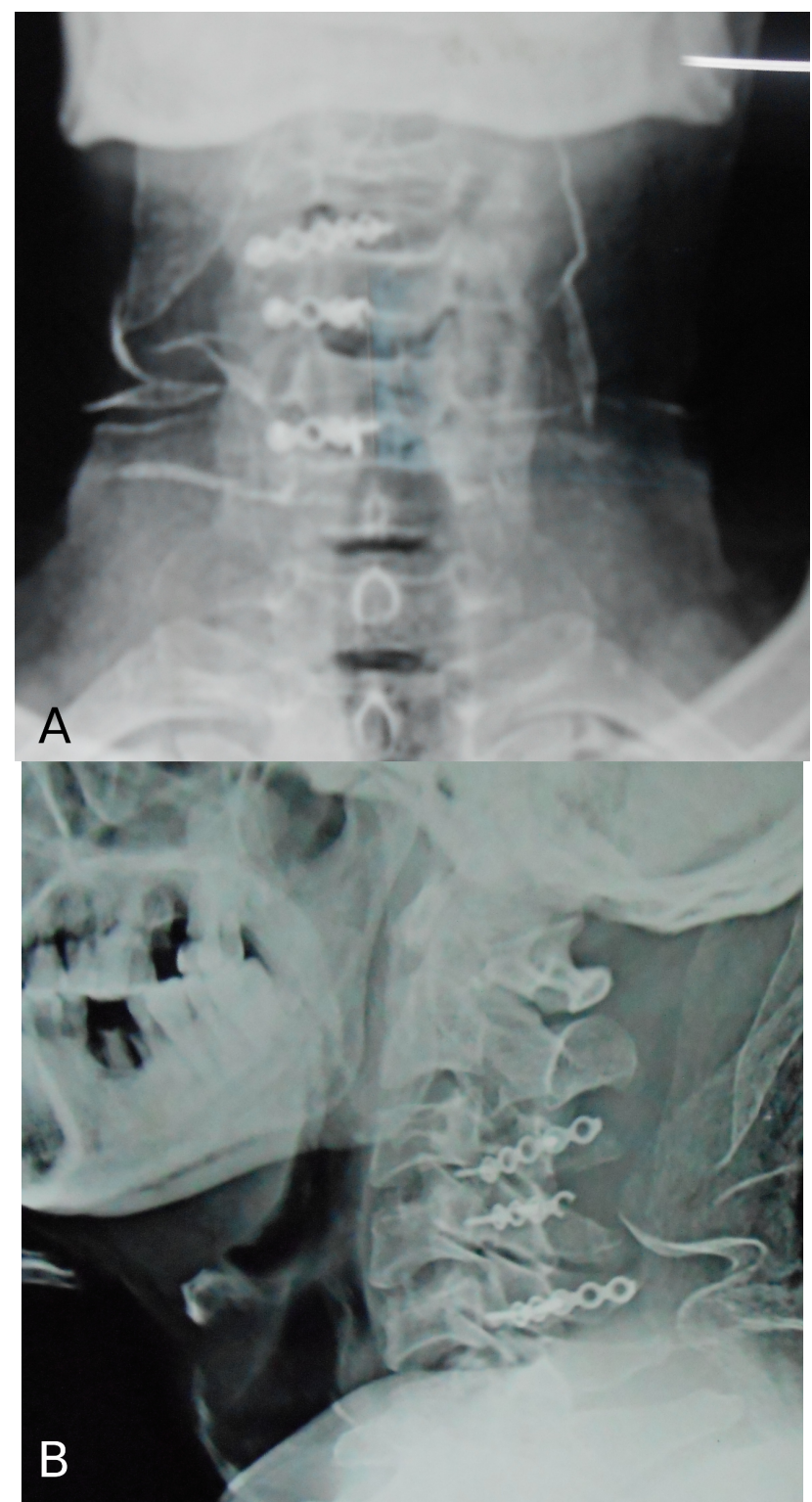

Fig. 5. Postoperative radiograph in AP and Lateral view with no signs of implant failure. two grades, two patients were unchanged and two had worsening of the Nurick grade. Radicular symptoms were improved significantly in all patients with radiculopathy $(8 / 8)$.

Thirteen out of 17 patients (76.47\%) demonstrated radiographic bony healing across the hinge osteotomy in the follow up period. Among the rest 4 patients (4/17), 2 patients $(2 / 17)$ gradually developed local kyphosis. Rest two patients $(2 / 17)$ were uneventful in the study period.

Regarding postoperative complications, two patients $(2 / 17)$ had nerve root injuries, one of them were isolated $\mathrm{C} 5$ and another one had combined $\mathrm{C} 5$ and $\mathrm{C} 6$ nerve root injuries. One patient had incidental durotomy and epidural bleeding in four patients (4/17). Incidences of superficial infection were in two cases $(2 / 17)$ which were effectively treated with antibiotics and no incidence of deep wound infection happened. There was no incidence of spinal cord contusion, epidural hematomas, or loss of fixation. In 2 of the 17 patients (2/17), loss of sagittal alignment occurred with development of a local kyphosis which was observed after four years of follow-up. These two patients complained about significant chronic neck pain in future. Rest (15/17) patients had not experienced the same. Some patients had complaint about the loss of range of motion in the follow-up period in variable extent. But we had not quantified the loss of $\mathrm{ROM}$ in all patients apart from the significant two persons $(02 / 17)$, as it was our goal in this fusion surgery.

\section{Discussion}

Management of CSM is often controversial. The results of non-operative treatment in the cases of progressive myelopathy are not acceptable. Furthermore, though there are numerous surgical strategies available but, there is no standard procedure. Controversies over the superiority of anterior or posterior approaches remain, but no consensus has been reached so far. Laminoplasty is one option among the wide range of posterior approaches.

There are essentially 3 useful surgical treatments for cervical spinal stenosis - anterior decompression and 
fusion with or without instrumentation, posterior laminectomy with or without fusion and instrumentation, and laminoplasty techniques, which may be instrumented. ${ }^{10}$ Via anterior approach, multilevel cervical discectomy with or without corpectomy and fusion can be performed. The main advantage of this approach is the possibility of direct spinal decompression through the removal of osteophytes, extruded discs, or thin longitudinal ligaments. But the draw-back about this technique is that, it is safe for up to three segments, ${ }^{11}$ after which the incidence of complications, such as pseudoarthrosis, graft migration and instrumentation failure ${ }^{12,13}$ rises; apart from the soft tissue related complications such as injury to the recurrent laryngeal nerve, the superior laryngeal nerve, esophagus and vertebral artery. The classic posterior approach for multisegmental myelopathy is the laminectomy. Despite impressive decompression results, this technique has been associated with postsurgery spine instability and kyphosis, ${ }^{14}$ post-surgery compression by fibrous tissue, and diminished clinical results over time specially when performed at more than three levels. ${ }^{15}$

Our results are descriptive and at the same time the clinical outcome in our study was comparable to other studies in the literature.

Regarding surgical time, we had a comparable result with the study of Leon Kaplan et al., ${ }^{16}$ which shows mean time of 2 hours 45 minutes. Initially we had operated for longer duration, but with the advancement of the learning curve the surgical time progressively diminished. Events such as dural tear and epidural bleeding had prolonged operating time and also needed transfusion.

Neurologic recovery is most likely related more to preoperative neurologic status, degree of myelopathy, the duration of symptoms, the etiology of stenosis etc. ${ }^{17}$ Age greater than 60 , a history of symptoms preoperatively for more than one year, presence of myelomalacia and cord atrophy are poor prognostic indicators ${ }^{18,19}$ and at the same time there is no guarantee that complete neurologic recovery will occur, particularly in patients with a long duration of symptomatology. According to the Nurick scale, we had improvement in $87 \%$ patients that is comparable with the study of Aluizio Augusto Arantes Júnior1et al. ${ }^{20}$ which shows improvement in $88 \%$ patients in a comparable study group.

Regarding complications, wound complications, such as deep infection or dehiscence, is a greater risk with laminoplasty compared to laminectomy as the lamina are rotated and held open. ${ }^{21}$ We have found the rate of deep infection and dehiscence to be extremely low $(0 / 17)$ in our laminoplasty patients. Avoidance of soft tissue complications is facilitated by paying meticulous attention to soft tissue handling, copious irrigation, thorough hemostasis, excision of necrotic soft tissue prior to closure, a watertight closure, subfascial drain placement, and perioperative antibiotics. Also we routinely debulk the more pronounced spinous processes prior to wound closure.

Neurologic deterioration is a potential risk with laminoplasty. This may be due to hematoma, inadequate decompression, traumatic surgical technique, re-stenosis or persistent stenosis due to inadequate raising of the lamina, fracture of the hinged lamina, or closure or dislodgment of the laminar opening. ${ }^{22,23}$ Nerve roots can be mechanically injured during laminoplasty procedures, particularly during decompression with a drill or punch. Isolated nerve root injuries are a particular concern with laminoplasty, however, and they occur around five to $11 \%$ of the time. ${ }^{24}$ This usually occurs on post-operative day two or three and is not commonly seen at immediate postoperative period. $\mathrm{C} 5$ is most often involved, though $\mathrm{C} 6, \mathrm{C} 7$, and rarely $\mathrm{C} 8$ root palsies have been described. ${ }^{25} \mathrm{It}$ is not clear what causes the $\mathrm{C} 5$ nerve root palsy but some postulate it is related to a traction injury to the nerve root. Not only are the $\mathrm{C} 5$ roots shorter and less forgiving to traction injuries, C5 is also at the apex of the lordotic cervical curve and, in general, it is at the centre of the laminoplasty. ${ }^{26}$ We had two cases $(2 / 17)$ of postoperative radiculopathy, both improved in next 8-12 months with the treatment of physical therapy and medications.

Development of post-operative neck pain is a concern in most of the patients. It is thought to be related to dissection around the facets and soft-tissue retraction, necrosis, and scarring. ${ }^{27}$ It is important to reattach the nuchal muscles to the $\mathrm{C} 2$ spinous 
process in order to maximize postoperative rehabilitation. The neck pain begins in the early post-op period. We had started early neck range of motion, NSAID medications and physical therapy to counter this complication as per our institutional custom with the help of a physiotherapist. Loss of sagittal alignment may potentiate neck pain further in future.

There is some controversy over the clinical significance of this loss of cervical motion. Some argue that range of motion after laminoplasty is crucial in addressing mechanical stress and avoiding adjacent segment degeneration and axial neck pain. ${ }^{28}$ On the other hand, some propose that post-laminoplasty stiffness contributes to resolution of OPLL, protects the spinal cord by limiting dynamic motion, and maximizes the potential for neurologic recovery. ${ }^{29}$

The range of worsening of cervical alignment in the form of kyphosis in long term follow-up usually varies from 22 to $53 \%$ in the available literatures. ${ }^{29,30}$ There is a paucity of literature on the correlation between kyphotic deformity and clinical or neurologic outcomes and even some data suggesting there is no such correlation. ${ }^{30,31,32}$ Augmenting a laminoplasty with modern instrumentation, however, has been shown to help preserve lordosis. ${ }^{33}$ We had noticed progressive kyphosis in $12 \%(2 / 17)$ of our patients at four year follow-up.

We had modified Hirabayashi open-door laminoplasty technique by adding titanium miniplates for rigid fixation to maintain the opening of the laminoplasty. Use of miniplates arose from the incidence of failures with other techniques for holding the osteotomy open - use of sutures or bone blocks, which are subject to potential failure or migration. In our series, we had not encountered any cases of fatigue failures and implant loosening till date. According to literature, this miniplate fixation has several reasons for its potential success. First, miniplates are subjected to minimal mechanical stress, as the lamina is still connected to the vertebral body. Second, the screws are not subjected to repetitive pullout forces because the lamina orientation directs the stresses at the bone-screw interface in a direction perpendicular to the screw (shear). Third, the closing unicortical laminar osteotomy provides progressive stability as it heals in the open position and relieves any stresses across the plate. ${ }^{34}$ Definitely the use of mini-plates to secure the widened spinal canal, as described in this paper, had made the entire procedure more reproducible with good neurological outcome and low complication rate even at a short duration of operative time.

This prospective study had several shortcomings, most notably the lack of a control group, relatively small patient population, and the lack of precise measurement of long-term final range of motion. Another limitation of the study was, most of the cases were performed in the initial two years of study. With gradual experience our operative time gets shortened and perioperative blood loss also gets reduced.

\section{Conclusion}

The open-door laminoplasty with instrumented fixation technique used in this study demonstrates a safe, easy and effective surgical procedure and provides an alternative for cases of multilevel cervical spondylotic myelopathy without deformation. This method is associated with a low rate of complications, a short operating time, and less incidence of post-surgery kyphosis or late instability. Furthermore, the two-open-doors laminoplasty technique does not require an autologous or heterologous graft or instrumentation. Furthermore, laminoplasty techniques are continuously being refined to address its shortcomings. Therefore, in the appropriate patient and with proper surgical technique, laminoplasty can be an excellent option for patients with multilevel cervical stenosis and myeloradiculopathy.

\section{References}

1. Lee TT, Green BA, Gromelski EB. Safety and stability of open-door cervical expansive laminoplasty. J Spinal Disord 1998; 11:12-15.

2. Tomita K, Kawahara N, Toribatake Y, Heller JG. Expansive midline T-saw laminoplasty (modified spinous process-splitting) for the management of cervical myelopathy. Spine 1998; 23:32-37.

3. Wang MC, Kreuter W, Wolfla CE, et al. Trends and variations in cervical spine surgery in the United 
States: Medicare beneficiaries, 1992 to 2005. Spine 2009; 34:955-961.

4. Murali Krishna Sayana, Hassan Jamil, and Ashley Poynton et al. Cervical Laminoplasty for Multilevel Cervical-Myelopathy Advances in Orthopaedics' Volume 2011, Article ID 241729, 4 pages doi:10.4061/2011/241729

5. Paramore CG, Dickman CA, Sonntag VK. Radiographic and clinical follow-up review of Caspar plates in 49 patients. J Neurosurg 1996;84(6):957-61. 6. Zdeblick TA, Bohlman HH. Cervical kyphosis and myelopathy: treatment by anterior corpectomy and strut grafting. J Bone Joint Surg (Am) 1989; 71:170-82.

7. Epstein JA. The surgical management of cervical spinal stenosis, spondylosis, and myeloradiculopathy by means of the posterior approach. Spine 1988; 13:864-9.

8. Y. Mukai, N. Hosono, H. Sakaura et al., "Laminoplasty for cervical myelopathy caused by subaxial lesions in rheumatoid arthritis," Journal of Neurosurgery, vol. 100, no. 1, pp. 7-12, 2004.

9. Nurick $S$ The pathogenesis of the spinal cord disorder associated with cervical spondylosis Brain 1972;95:87-100.

10. Edwards CC 2nd, Riew KD, Anderson PA, Hilibrand AS, Vaccaro AF. Cervical myelopathy. Current diagnostic and treatment strategies. Spine J. 2003; 3(1):68-81.

11. Arantes A, Gusmão S, Rubinstein F, Oliveira R. Microsurgical anatomy of the recurrent laryngeal nerve: applications on the anterior approach to the cervical spine. Arq Neuropsiquiatr 2004; 62:707-710. 12. Edwards, C, Heller, J, Morikami, H, et al. Corpectomy versus laminoplasty for multi-level cervical myelopathy: An independent matched cohort study. Spine 2002; 27:1168-1175.

13. Vaccaro, AR, Falatyn, SP, Scuderi, GJ, et al. Early failure of long segment anterior cervical plate fixation. J Spinal Disord 1998; 11:410-415. 14. Yonenobu, K, Okada, K, Fuji, T, Fujiwara, K, Yamashita, K, Ono, K. Causes of neurologic deterioration following surgical treatment of cervical myelopathy. Spine 1986; 11:818-823.

15. Dai R, Ni B, Yuan W, Jia L. Radiculopathy after laminectomy for cervical compression myelopathy. J Bone Joint Surg Br 1998; 80:846-84.
16. Leon Kaplan et al, Canal expansive laminoplasty in the management of Cervical spondylotic Myelopathy, IMAJ. Vol 8 • August 2006. 548-552.

17. Kimura I, Shingu H, Nasu Y. Long-term followup of cervical spondylotic myelopathy treated by canal expansive laminoplasty. J Bone Joint Surg (Br) 1995; 77:956-61.

18. T. T. Lee, G. R. Manzano, and B. A. Green, "Modified open-door cervical expansive laminoplasty for spondylotic myelopathy: operative technique, outcome, and predictors for gait improvement," Journal of Neurosurgery, vol. 86, no. 1, pp. 64-68, 1997.

19. K. Satomi, J. Ogawa, Y. Ishii, and K.

Hirabayashi, "Short-term complications and longterm results of expansive open-door laminoplasty for cervical stenotic myelopathy," Spine Journal, vol. 1, no. 1, pp. 26-30, 2001.

20. Aluizio Augusto Arantes Júnior et al, A new expansive two-open-door laminoplasty for multilevel spondylotic myelopathy: technical report and followup results. Arq Neuropsiquiatr 2014;72(1):49-54.

21. K. Yonenobu, E. Wada, and K. Ono, "Laminoplasty," in The Cervical Spine, C. R. Clark, Ed., pp. 1057-1071, Lippincott Williams and Wilkins, Philadelphia, Pa, USA, 2005.

22. J. Mochida, T. Nomura, M. Chiba, K. Nishimura, and E.Toh, "Modified expansive open-door laminoplasty in cervical myelopathy," Journal of Spinal Disorders, vol. 12, no. 5, pp. 386-391, 1999. 23. Y. Morio, K. Yamamoto, R. Teshima, H. Nagashima, and H. Hagino, "Clinicoradiologic study of cervical laminoplasty with posterolateral fusion or bone graft," Spine, vol. 25, no. 2, pp.190-196, 2000. 24. P. G. Matz, P. A. Anderson, M. W. Groff et al., "Cervical laminoplasty for the treatment of cervical degenerative myelopathy," Journal of Neurosurgery, vol. 11, no. 2, pp. 157-169, 2009.

25. Minoda Y, Nakamura H, Konishi S, et al. Palsy of the $\mathrm{C} 5$ nerve root after mid-sagittal splitting laminoplasty of the cervical spine. Spine 2003; 28:1123-7.

26. Y. Uematsu, Y. Tokuhashi, and H. Matsuzaki, "Radiculopathy after laminoplasty of the cervical spine," Spine, vol. 23, no. 19, pp. 2057-2062, 1998. 27. T. Takeuchi and Y. Shono, "Importance of preserving the $\mathrm{C} 7$ spinous process and attached nuchal 
ligament in French-door laminoplasty to reduce postoperative axial symptoms," European Spine Journal, vol. 16, no. 9, pp. 1417-1422, 2007.

28. C. I. Shaffrey, G.C.Wiggins, C. B.Piccirilli, J.N. Young, and L. R. Lovell, "Modified open-door laminoplasty for treatment of neurological deficits in younger patients with congenital spinal stenosis: analysis of clinical and radiographic data," Journal of Neurosurgery, vol. 90, no. 4, pp. 170-177, 1999.

29. Y. Morio, K. Yamamoto, R. Teshima, H. Nagashima, and H. Hagino, "Clinicoradiologic study of cervical laminoplasty with posterolateral fusion or bone graft," Spine, vol. 25, no. 2, pp. 190-196, 2000. 30. K. Miyazaki, K. Tada, Y. Matsuda, M. Okuno, T. Yasuda, and H. Murakami, "Posterior extensive simultaneous multi-segment decompression with posterolateral fusion for cervical myelopathy with cervical instability and kyphotic and/or shaped deformities," Spine, vol. 14, no. 11, pp. 1160-1170, 1989.

31. A. Seichi, K. Takeshita, I. Ohishi et al., "Longterm results of double-door laminoplasty for cervical stenotic myelopathy," Spine, vol. 26, no. 5, pp. 479-487, 2001.

32. E.Wada, S. Suzuki, A. Kanazawa, T.Matsuoka, S.Miyamoto, and K. Yonenobu, "Subtotal corpectomy versus laminoplasty for multilevel cervical spondylotic myelopathy: a long-term follow-up study over 10 years," Spine, vol. 26, no. 13, pp. 1443-1447, 2001.
33. M. F. O'Brien, D. Peterson, A. T. H. Casey, and H. A. Crockard, "A novel technique for laminoplasty augmentation of spinal canal area using titanium miniplate stabilization: a computerized morphometric analysis," Spine, vol. 21, no. 4, pp. 474-483, 1996. 34. John R. Dimar II, Kelly R. Bratcher, Dylan C. Brock, BS, Steven D. Glassman, Mitchell J. Campbell, and Leah Y. Carreon, Instrumented Open-Door Laminoplasty as Treatment for Cervical Myelopathy in 104 Patients, The American Journal of Orthopaedics, July 2009, E 123-128.

\section{Disclosures}

The authors declare no relevant disclosures and no conflicts of interest.

\section{Corresponding Author}

Dr. Subhadip Mandal, c/o Dr. Subhas ch. Mandal, North-schooldanga, Sukanta-statue, Bankura, West Bengal, India 722101. Subhadip.mandal007@gmail.com.

Published 29 April 2016. This manuscript is generously published free of charge by ISASS, the International Society for the Advancement of Spine Surgery. Copyright $\odot 2016$ ISASS. To see more or order reprints or permissions, see http://ijssurgery.com. 